\title{
Development and Evaluation of Nano-Silica Dispersed Polyurethane Based Coatings for Improved Anti-Graffiti and Scratch Resistance
}

\author{
Priyanka Adapala, Swati Gaur, Ravindra G. Puri, Anand S. Khanna \\ Department of Metallurgical Engineering \& Materials Science, IIT Bombay, Mumbai, India \\ Email: hydpriya.1911@gmail.com,gaurswat@gmail.com,ravigpuri@gmail.com, anandkh52@gmail.com
}

Received 18 November 2015; accepted 21 December 2015; published 24 December 2015

Copyright (C) 2015 by authors and Scientific Research Publishing Inc.

This work is licensed under the Creative Commons Attribution International License (CC BY).

http://creativecommons.org/licenses/by/4.0/

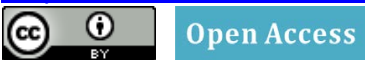

\begin{abstract}
Polyurethane based anti-graffiti coatings have been developed by incorporating varying amounts of OH-functional Silicone modified polyacrylate. Optimization of Silicone polyacrylate concentration in neat PU was done by testing its performance for graffiti resistance. Tests which include static contact angle measurements with water and spray paint, visual inspection of stain removal and color change measurements were performed. It was observed that $5 \mathrm{wt} \%$ of Silicone polyacrylate in the neat PU showed $95 \%$ stain removability. These coatings showed excellent graffiti resistance but poor mechanical properties. Hence modification of these coatings was done by nano-particle incorporation. Nano-silica particle concentration was optimized for surface mechanical properties such as surface hardness, elastic modulus and scratch resistance. FEG-TEM revealed that nano-silica particles were uniformly distributed over the surface. $5 \mathrm{wt} \%$ nano-silica particle additions in PU-5 wt \% silicone polyacrylate base showed superior mechanical properties than other concentrations. Color change measurements showed that nano-silica particle addition had no effect on its graffiti resistance. Hence PU-5 wt \% silicone polyacrylate, 5 wt \% nano-silica showed excellent graffiti resistance and mechanical properties.
\end{abstract}

\section{Keywords}

Silicone Modified Polyacrylate, Nano-Silica Particles, Anti-Graffiti, Scratch Resistance

\section{Introduction}

The term graffiti can be defined as an activity which includes scribbling, drawing, painting done deliberately

How to cite this paper: Adapala, P., Gaur, S., Puri, R.G. and Khanna, A.S. (2015) Development and Evaluation of Nano-Silica Dispersed Polyurethane Based Coatings for Improved Anti-Graffiti and Scratch Resistance. Open Journal of Applied Sciences, 5, 808-818. http://dx.doi.org/10.4236/ojapps.2015.512077 
causing unauthorized defacement of the surfaces which may include metallic structures, buildings, monuments etc. It is derived from Italian word Graffiare which means scratch. In recent times, graffiti in the form of spray paints is being considered as art. However, graffiti on ancient buildings and monuments is considered as vandalism. The impact of graffiti on artefacts of cultural heritage is very high in both social and economic terms because graffiti degrades the sprayed region and also the affected bodies are devaluated. Cleaning of graffiti also involves high costs. Although, the exact cost of the graffiti removal is not known, the estimates say that it is around 700 million dollars for Germany, 1.5 dollars for London, 12 billion dollars in the US annually [1].

The general mechanism of these coatings is based on developing a low energy surface using the components such as fluoro, silicone and per-fluoro components that the graffiti solvent does not wet the surface. It enables easy cleaning thereby leading to the longevity of the coating. This also avoids usage of aggressive and powerful chemicals generally adopted in cleaning procedures [2].

Polysiloxanes possess the properties of hydrophobicity, thermal stability and biological resistance [3]. Feng et al. investigated the surface properties of polyurethanes modified by polysiloxane [4]. Mohammad Rabea et al. studied the surface properties of these coatings against UV exposure. They have tested for the effects of this additive on the surface chemistry and anti-graffiti properties [5].

Nano-silica and Nano-alumina particles are generally used for improving mechanical properties of coatings. On Mohs scale of hardness, silica and alumina have hardness 9 and 7 respectively and hence they are the widely used nanoparticles for scratch and abrasion coatings [6]. Nano-silica particles are preferred to nano-alumina as they do not affect the transparency of the coating. Nano-silica particles possess low refractive index, high modulus and hardness [7].

In this work neat polyurethane was modified by $\mathrm{OH}$-functional silicone polyacrylate for anti-graffiti property. Optimization of $\mathrm{OH}$-functional silicone polyacrylate concentration was done based on their graffiti resistance. It was observed that they possessed inferior mechanical properties. Nanoparticles were incorporated into these coatings to enable improvement in the surface mechanical properties and scratch resistance. Nano-silica particles were added as their refractive index matches with the resin based coatings. Optimization of nano-silica particle concentration was done based on their mechanical behavior and scratch resistance. Mechanical, antigraffiti and surface properties of the final formulation were evaluated.

\section{Experimental Details}

\subsection{Materials}

The acrylic polyol (Macrynal 510) procured from Allnex group and aliphatic polyisocyanate hardener (Desmodur N3390) supplied by Desmodur group were used to synthesize polyurethane with -NCO: - OH ratio 1.1:1. Surface treated Nano-silica dispersion (BYK 3650). OH-functional silicone modified polyacrylate (BYK 3700). The solvent used, Methoxy propyl acetate was purchased from Sigma-Aldrich group.

\subsection{Coating Procedure}

Initially, the mild steel panels of size $6 \times 4 \mathrm{~cm}^{2}$ were coated with white polyurethane paint (Interthane 990) using spray. The coating thickness was $100 \mu \mathrm{m}$. The coating was left to air-dry for 2 days and then kept for drying at $70^{\circ} \mathrm{C}$ in the furnace for $5 \mathrm{~h}$. This basically plays the role of base coat.

The formulation of polyurethane transparent coating i.e., without any additives, is given below in Table 1 . Amount of polyisocyanate required for $100 \mathrm{~g}$ of polyol is calculated using the following formula

$$
\frac{42 \times 100 \times(\mathrm{NVM} \%) \times(\mathrm{NCO}: \mathrm{OH} \text { ratio }) \times \mathrm{OH} \%}{17 \times \mathrm{NCO} \%}
$$

Coating formulations have been made by substitution of acrylic polyol content with silicone polyacrylate additive ranging from 1 - $6 \mathrm{wt} \%$. Optimization of the polyacrylate content was done by testing for their graffiti resistance and it was further modified with Nano-silica particles for other properties. Nano-silica particles in the range of $1-7 \mathrm{wt} \%$ was incorporated in the existing system. Optimization of Nano-silica dispersion was done by testing the developed coatings for mechanical properties and scratch resistance. Coatings of above mentioned formulations were prepared by ultra-sonication of all the components for $20 \mathrm{~min}$ and then the isocyanate hardener was added after which moderate manual mixing was done for $10 \mathrm{~min}$. 
Table 1. Formulation of Neat PU.

\begin{tabular}{ccc}
\hline Ingredient & Quantity (g) & Remarks \\
\hline Macrynal SM 510n & 10.0 & Hydroxyl functional polyol resin \\
Methoxy Propyl Acetate & 4.0 & Solvent \\
10\% DBTDL solution in xylene & 0.1 & Catalyst \\
Desmodur N3390 & 3.7 & Aliphatic polyisocyanate \\
\hline
\end{tabular}

\section{Testing and Characterisation Techniques}

\subsection{FTIR Analysis}

FTIR analysis was used to characterize the structure of Polyurethane and silicone modified polyurethane. The viscous resin samples were directly applied by dabbing into $\mathrm{KBr}$ pellets. The IR spectra were recorded on a Perkin Elmer ATR spectrum 100 FTIR spectrophotometer in the range of $400-4000 \mathrm{~cm}^{-1}$ at a resolution of $4 \mathrm{~cm}^{-1}$ for 32 scans [8].

\subsection{Contact Angle Measurements}

Contact angle measurements were carried out by dropping water and the spray paint over the surface. The contact angles were measured using an instrument called goniometer equipped with CCD camera (Model Phoenix 300, software: Surfaceware 7) at room temperature. A droplet of volume around $10-15 \mu \mathrm{L}$ was dropped on the coated surface using a micro-syringe and the contact angle was measured [9].

\subsection{Stain Removal Test- Visual Inspection}

The coated steel samples of dimensions $6 \times 4 \mathrm{~cm}^{2}$ were tested for the efficiency of graffiti removal by initially marking a circular region of $3 \mathrm{~cm}$ radius using a black permanent marker pen (CAMLIN). The stain was allowed to dry at ambient temperature for about $10 \mathrm{~h}$. Then stain removal was done using a cotton wool dipped in $80 \%$ methanol and wiped off gently. The surfaces were visually inspected for the stain removing ability [10].

\subsection{Color Change Measurements}

Color change measurements were carried out using an instrument named Spectro-Guide, Model No: 6834 supplied by BYK Gardener. CIE, ComissionInternationale de l'Eclairage (International Commission on Illumination) models were used to determine the color changes of the coated surfaces due to graffiti. Measurements were carried out on graffiti applied coated surfaces, before and after its removal $\Delta \mathrm{L}, \Delta \mathrm{a}$ and $\Delta \mathrm{b}$ are the differences in lightness (L), red/green ( + a represents red, - a represents green), blue/yellow (+b represents blue and $-b$ represents yellow). The total color change was determined by $\Delta \mathrm{E}$, which is mathematically calculated by the following formula

$$
\Delta E=\left[(\Delta L)^{2}+(\Delta a)^{2}+(\Delta b)^{2}\right]^{1 / 2}
$$

The steel panels of $6 \times 4 \mathrm{~cm}^{2}$ dimensions were coated with varying formulations and were tested for color change due to graffiti. A black permanent marker pen (CAMLIN) was used to darken a region of a circle with radius $3 \mathrm{~cm}$. The marked regions were dried for $10 \mathrm{~h}$ and then cotton wool dipped in $80 \%$ methanol was used to remove the stain. The readings of $\mathrm{L}, \mathrm{a}, \mathrm{b}$ and $\mathrm{E}$ were taken before and after the trial of stain removal [11].

\subsection{Dispersion Studies}

The dispersion of nanoparticles on the coated surfaces was observed under Field Emission Gun Transmission Electron Microscopy (Philips, CM200). The aim was to determine the particle size of the silica particles and observe the distribution, alignment and orientation of nano-silica particles in the coated film thereby correlating them with the mechanical properties offered by them. The coating films were microtomed and then they were seen for the microstructure under FEGTEM [12]. 


\subsection{Nano-Indenter-Surface Hardness Study}

Nano indentation was done using an instrument called Triboindenter, Model No: TI-900 supplied by Hysitron. The tip used for Nano indentation measurement was berkovich (three-sided pyramidal diamond tip) with a total included angle of $142.3^{\circ}$. The mechanical properties acquired in the coated surfaces do not solely depend upon the film coating but also depend on the load applied and the tip geometry. The maximum load used was $500 \mu \mathrm{N}$, maximum load was reached in $10 \mathrm{sec}$ and the load was applied for $5 \mathrm{sec}$ after which unloading was done. The maximum penetration was $10 \%$ of the sample thickness. The elastic modulus and hardness of the coated samples were calculated using the Oliver-Pharr method [13].

\subsection{Scratch Resistance Measurements}

The same instrument used for Nano-indenter was used for performing the scratch test and determining the coefficient of friction as well. Five sets of Nano-scratch tests have been carried out each at maximum normal load of $1000 \mu \mathrm{N}$. The stage position moved to $-5 \mu \mathrm{m}$ with zero normal load to trace across the surface at the set point. Then, the stage held at this position for 3 seconds to set the indenter on the surface. Thereafter, the stage moved form $-5 \mu \mathrm{m}$ to $\pm 5 \mu \mathrm{m}$ in 30 seconds. During this time, the normal load ramped up from zero to the maximum load, scratched the surface to the length of $10 \mu \mathrm{m}$. After that, the stage position was held for 3 seconds for stabilization. Thereafter, the stage position moved to zero. During this time, the normal load was set to zero to prevent deformation of the surface [14].

\section{Results and Discussions}

\subsection{Optimization of OH-Functional Silicone Modified Polyacrylate in Neat PU}

OH-functional silicone polyacrylate was added to the neat PU in varying concentrations to improve graffiti resistance. Optimization was done by testing its performance in contact angle, stain removability and color change measurements.

\subsubsection{Structural Analysis-FTIR}

FTIR plot of PU-5 wt \% Silicone polyacrylate in comparison with neat PU is given in Figure 1. Stretching vibrations of N-H groups in urethanes at $3322 \mathrm{~cm}^{-1}$ and the broad $-\mathrm{OH}$ stretch at $3570-3200 \mathrm{~cm} \mathrm{~cm}^{-1}$ were seen overlapping for neat PU. The absence of $-\mathrm{OH}$ stretch indicated that all free $-\mathrm{OH}$ groups have reacted with $-\mathrm{NCO}$ group. Also, it was observed that $\mathrm{OH}$ peak intensity decreased at $3500 \mathrm{~cm}^{-1}$ showing increased hydrophobicity for all modified PU coatings.

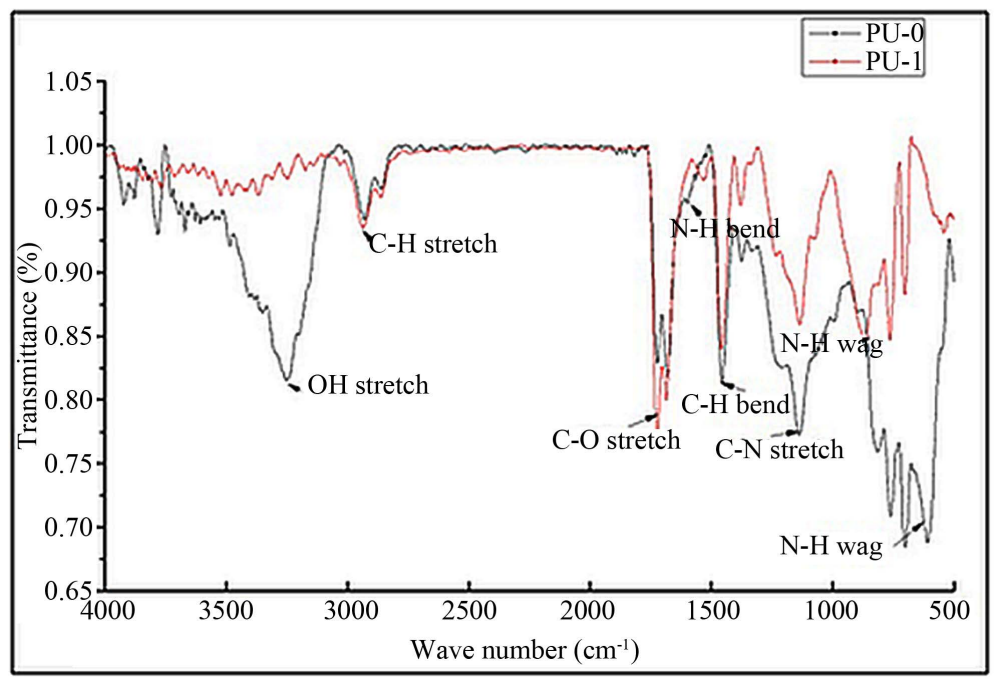

Figure 1. FTIR plot of PU-5 wt \% silicone polyacrylate in comparison with Neat PU. 
It was observed that a broad -OH stretch was found in neat PU coating. But the absence of OH in PU-5 wt \% Silicone polyacrylate showed that the free $-\mathrm{OH}$ has reacted with $-\mathrm{NCO}$ groups. The absence of $-\mathrm{OH}$ group also indicated that hydrophobicity had been induced in these coatings.

\subsubsection{Surface Studies-Contact Angle Measurement}

Contact angle measurements were carried out on the developed coating systems using water and spray paint and the results are listed below. From the results shown in Figure 2, it was observed that with an increase in the concentration of the silicone polyacrylate content the contact angles of both the water and the spray paint have increased. However, the maximum contact angle was observed at $5 \mathrm{wt} \%$ of polyacrylate beyond which there was no significant change in the contact angle. This can be attributed to an excess migration of silicone polyacrylate on to the surface leading to saturation and causing non-uniformity in the coating.

In Figure 2, it was also observed that the contact angle of the spray paint was slightly lower than that of the water at a given concentration of Silicone polyacrylate. The reason for this was surface tension of spray paint being lower than that of the water over the coating surface.

\subsubsection{Stain Removal Test}

Stain removal test was carried out on PU with varying concentration of silicone polyacrylate. The stain marked on all the samples appeared almost similar and is shown in Figure 3(a) The coated surfaces, after stain removal, showed that the neat PU surface had most of the stain retained on it and can be seen in Figure 3(b). With the increase in the concentration of the silicone polyacrylate in PU, stain removability increased. In the PU-5 wt \% silicone polyacrylate, no trace of stain was observed after it has been removed and is shown in Figure 3(c). Even PU-6 wt \% showed similar performance, having no stain left on it. This test was visually inspected. To exactly quantify the amount of stain retained, these samples were subjected to color change measurements using spectrometer.

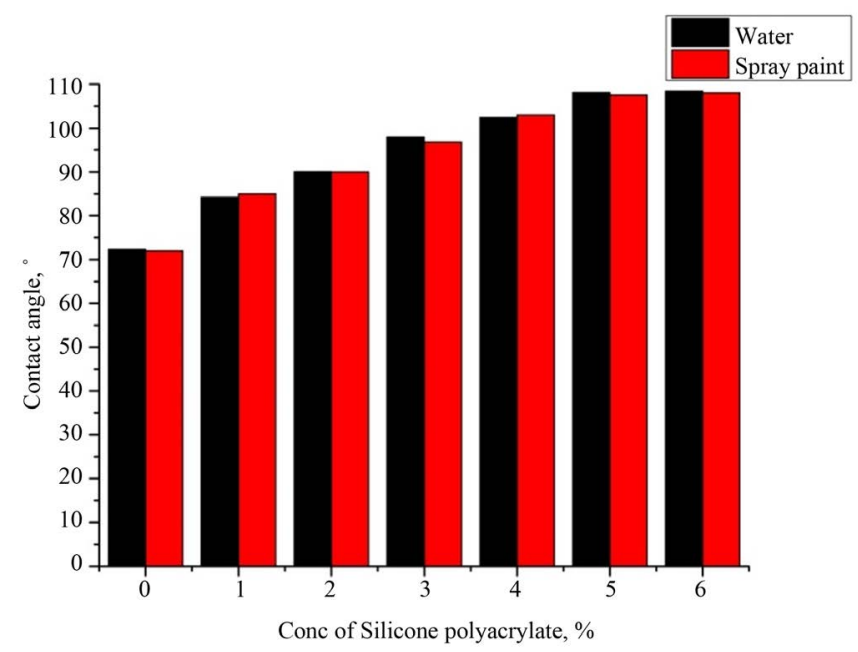

Figure 2. Plot showing trend of contact angle of water and spray paint with increase in content of silicone polyacrylate.

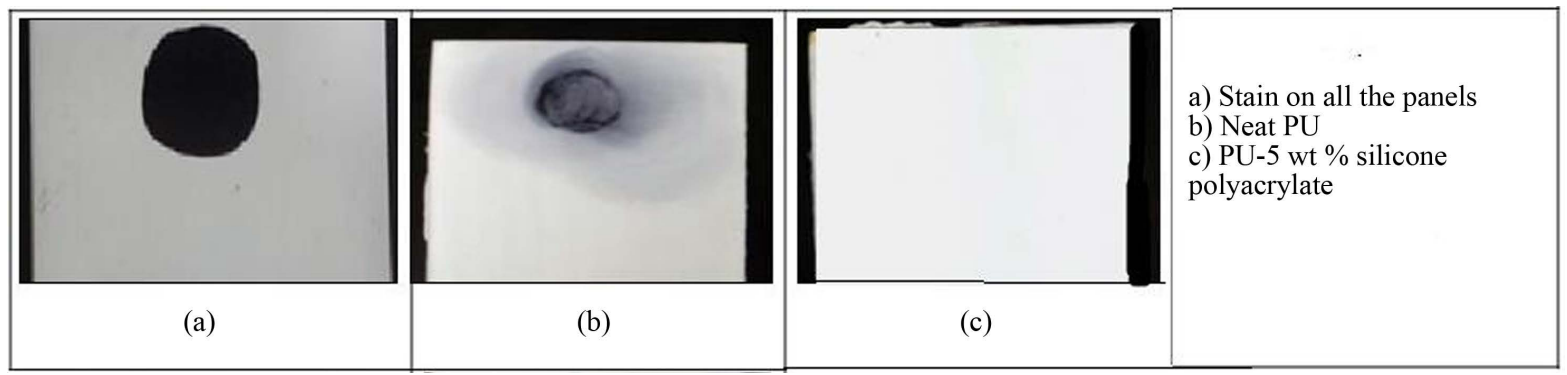

Figure 3. Stain removability tests on coated surfaces with PU and varying content of silicone polyacrylate. 


\subsubsection{Color Change Measurements}

To quantify the color change in the coatings before and after graffiti removal, the color attributes $\mathrm{L}, \mathrm{a}^{*}$ and $\mathrm{b}^{*}$. All the color attributes and their corresponding color change values $(\Delta \mathrm{E})$ are listed in the Table 2.

The color change was quantified by considering the value $\Delta \mathrm{E}$. It signifies the color from the graffiti which has been removed in cleaning technique. From the color change measurements, it was observed that with an increase in silicone polyacrylate content $\Delta \mathrm{E}$ has increased drastically. It showed there was a significant color change before and after graffiti removal on the PU coating and it has increased with increase in silicone content. But beyond $5 \mathrm{wt} \%$ of its concentration there was no significant change in the color change measurement as there was saturation of silicone polyacrylate on the surface of the coating.

The improvement in the contact angle of water and spray paint and increase in the graffiti resistance observed through color change measurements over the coated surface can be explained by Figure 4. Considering the basic structure of $\mathrm{OH}$-functional silicone polyacrylate, it contains $\mathrm{OH}$ groups. In the curing mechanism of polyurethane, - NCO from the polyisocyanate component reacted with few $\mathrm{OH}$ molecules of silicone polyacrylate component, thus got attached to the cross-linked structure and the others reacted with $\mathrm{OH}$ molecules of polyol resin. This was the reason for which the concentration of silicone polyacrylate added should be compensated by

Table 2. Color change measurements of PU coating with varying content of silicone polyacrylate.

\begin{tabular}{|c|c|c|c|c|c|c|c|c|c|c|c|}
\hline \multirow{2}{*}{ \% Conc } & \multicolumn{3}{|c|}{ Before removal } & \multicolumn{3}{|c|}{ After removal } & \multicolumn{5}{|c|}{ Difference } \\
\hline & $\mathbf{L}$ & a & B & $\mathbf{L}$ & a & b & $\Delta \mathbf{L}$ & $\Delta \mathbf{a}$ & $\Delta \mathbf{b}$ & $\Delta \mathbf{G}$ & $\Delta \mathbf{E}$ \\
\hline \multirow{2}{*}{$\mathbf{0}$} & 29.80 & 2.40 & 0.72 & 44.81 & 0.94 & 6.38 & 14.92 & -1.48 & -7.14 & -21.3 & 16.6 \\
\hline & 29.76 & 2.38 & 0.69 & 43.7 & 0.86 & 6.50 & 14.5 & -1.66 & -6.8 & -22 & 17.0 \\
\hline \multirow{2}{*}{1} & 32.17 & 2.18 & 0.53 & 53.21 & 1.08 & 6.02 & 21.04 & -1.10 & -5.49 & 29.6 & 21.77 \\
\hline & 32.0 & 2.12 & 0.4 & 51.8 & 1.9 & 6.04 & 22.01 & -1.06 & -5.36 & 28.7 & 22.06 \\
\hline \multirow{2}{*}{2} & 29.87 & 2.42 & 0.63 & 63.09 & 0.33 & 4.91 & 33.21 & -2.08 & -5.54 & -9.2 & 33.73 \\
\hline & 29.89 & 2.51 & 0.71 & 64.10 & 0.34 & 4.76 & 32.08 & -2.16 & -5.67 & -9.8 & 34.0 \\
\hline \multirow{2}{*}{3} & 34.23 & 1.79 & 0.08 & 73.98 & 1.10 & 3.03 & 40.67 & -3.0 & -3.05 & 36.4 & 40.89 \\
\hline & 34.22 & 1.8 & 0.09 & 74.0 & 1.21 & 3.01 & 41.81 & -3.20 & -3.09 & 36.7 & 41.0 \\
\hline \multirow{2}{*}{4} & 34.24 & 1.91 & 0.04 & 85.25 & 1.34 & 0.66 & 52.01 & -3.25 & -0.70 & 27.2 & 52.11 \\
\hline & 33.10 & 1.88 & 0.33 & 84.91 & 1.41 & 0.71 & 51.91 & -3.19 & -0.67 & 26.8 & 54.12 \\
\hline \multirow{2}{*}{5} & 37.89 & 0.91 & 0.01 & 94.43 & -1.12 & 0.41 & 56.54 & -2.03 & -0.31 & 20.1 & 56.58 \\
\hline & 37.78 & 0.89 & 0.02 & 94.54 & -1.42 & 0.55 & 56.76 & -2.31 & -0.53 & 22.2 & 55.80 \\
\hline \multirow{2}{*}{6} & 37.66 & 0.87 & 0.03 & 95.10 & -1.39 & 0.46 & 57.63 & -2.29 & -0.55 & 23.4 & 55.90 \\
\hline & 37.45 & 0.79 & 0.02 & 96.01 & -1.35 & 0.42 & 56.91 & -2.31 & -0.47 & 22.9 & 56.21 \\
\hline
\end{tabular}

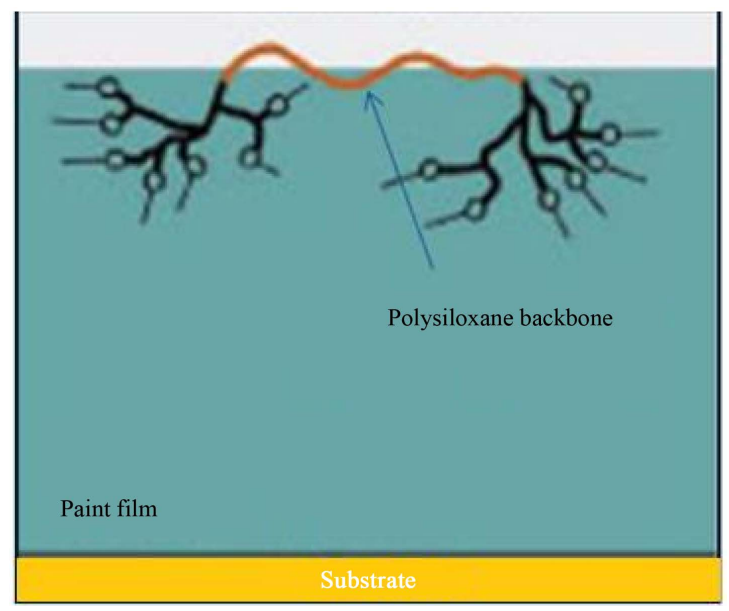

Figure 4. Mechanism involved in hydrophobicity due to incorporation of silicone polyacrylate in the coating. 
removal of the same concentration of polyol from the formulation so that no $\mathrm{OH}$ content in either of the components remains unreacted. One end of the siliconated structure is bonded with the -NCO component, the free end i.e., $\mathrm{H}^{+}$migrated to the surface and lowered the surface energy. It was noted that beyond a certain concentration, further addition of silicone polyacrylate had no effect on graffiti resistance as the surface was saturated with the additive chain. This concentration was considered as the optimum concentration. The decrease in the contact angle beyond $5 \mathrm{wt} \%$ can be attributed to this principle. Higher the concentration of silicone polyacrylate greater was the number of unreacted hydroxyl groups of polyol which led to a decrease in the hydrophobic effect due to the accumulation of silicone components on the surface.

\subsection{Optimization of Nano-Silica Particles in PU-5 wt \% Silicone Polyacrylate for Improvement in Mechanical Properties}

\subsubsection{FEG-TEM Analysis}

1) Nano particle dispersion

FEG-TEM analysis was carried out on the as received nano-silica particle dispersion to confirm the particle size. Images at $20 \mathrm{~nm}, 50 \mathrm{~nm}$ and $100 \mathrm{~nm}$ resolutions were taken. Figure 5 As the magnification increased the contrast between the particles and the surrounding area was observed to decrease. It was observed that the particles were well dispersed in the solvent without any agglomeration. The particles were spherical in shape. The spherical diffracted pattern of the particles proves that the dispersed particles were amorphous. Few particles were chosen randomly and their particles sizes were marked. By this, the average particle size of the particles was calculated and found to be $25 \mathrm{~nm}$.

2) Coating with nanoparticle dispersion

Free films of PU-5 wt \% silicone polyacrylate and varying content of nano-silica dispersion i.e., from 1 - $7 \mathrm{wt} \%$ were prepared. The thickness of the films was $50 \mu \mathrm{m}$. The films were microtomed to get a nanometer-sized film. The films were taken on a copper grid for FEG-TEM analysis.
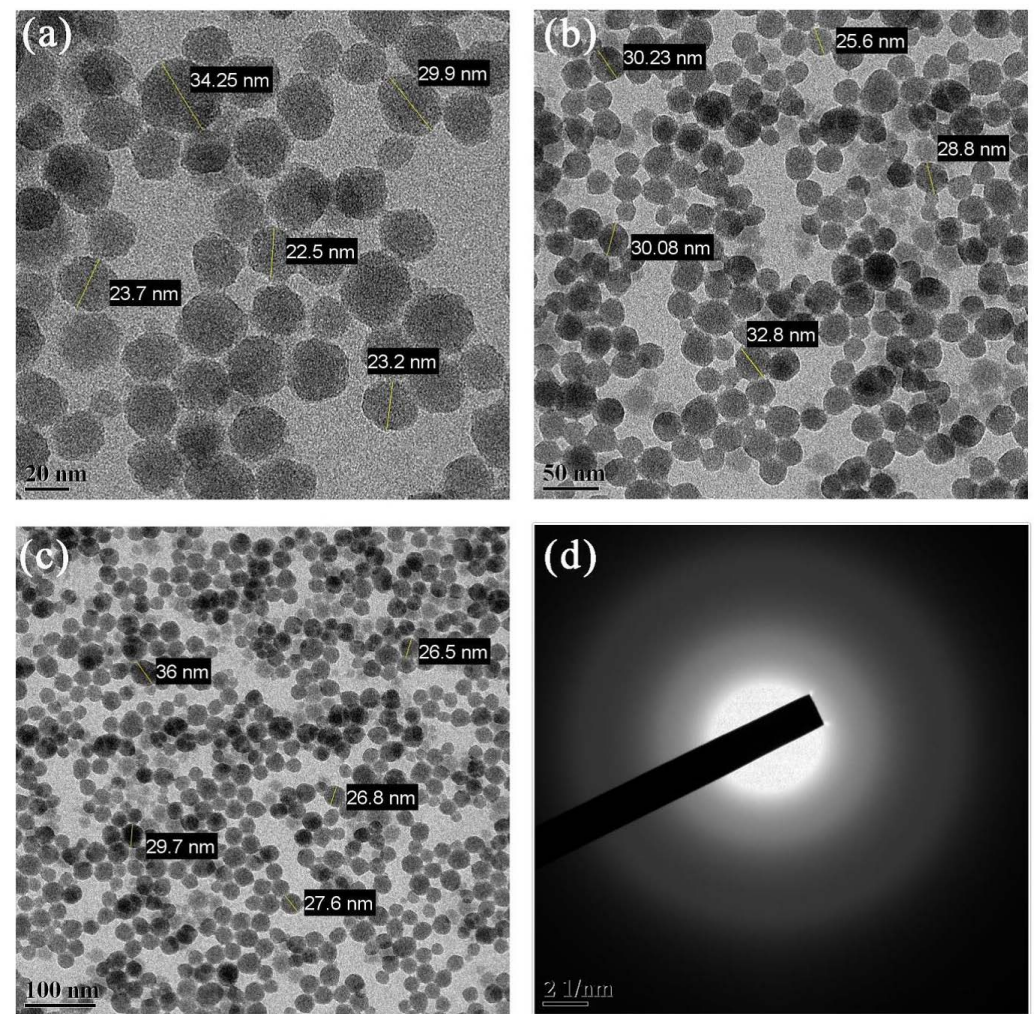

Figure 5. FEG-TEM images of Nano-silica particle dispersion and their particle sizes at various resolutions (a) $20 \mathrm{~nm}$ (b) $50 \mathrm{~nm}$ (c) $100 \mathrm{~nm}$ and (d) Diffraction pattern. 
Images of the films PU-5 wt \% silicone polyacrylate and content of nano-silica particles ranging from 1 - 5 wt \% showed that the particles migrated to the surface and are uniformly distributed throughout the surface of the film. A clear distinguish was observed between the surface and the sub-surface region. This can be seen in Figure 6, which is the image of PU-5 wt \% silicone polyacrylate and 5 wt \% nano-silica particle dispersion.

Beyond $5 \mathrm{wt} \%$ of nano-silica particle addition in the PU-5 wt \% silicone polyacrylate system, the image showed agglomeration of nano-silica particles. Figure 7 of PU-5 wt \% silicone polyacrylate and 7 wt \% nano-silica particles shows agglomeration of nano-particles. Above $5 \mathrm{wt} \%$ of nano-silica particles in the system, these particles formed clusters. This led to inhomogeneity in the distribution of particles.

\subsubsection{Mechanical Properties Determination Using Nano-Indenter}

Surface hardness, elastic modulus and the coefficient of friction of the system with PU-5 wt \% silicone polyacrylate and varying the content of nano-silica particles from 1 - $7 \mathrm{wt} \%$ were measured using nano indenter. Figure 8 is a plot showing a variation of surface hardness, elastic modulus and the coefficient of friction with varying content of nano-silica particles. Every value on the plot was the average of three measurements. The plot showed that with an increase in the nano-silica content, surface hardness and the elastic modulus have increased. On further addition, at 6 wt \% there was a sudden fall in surface hardness. The elastic modulus has not shown a significant change in the elastic modulus. The plot of coefficient of friction with varying content of nano-silica particles showed a decreasing trend. Further increase in the nano-silica content beyond $5 \mathrm{wt} \%$ showed no significant change. The coefficient of friction almost remained constant.
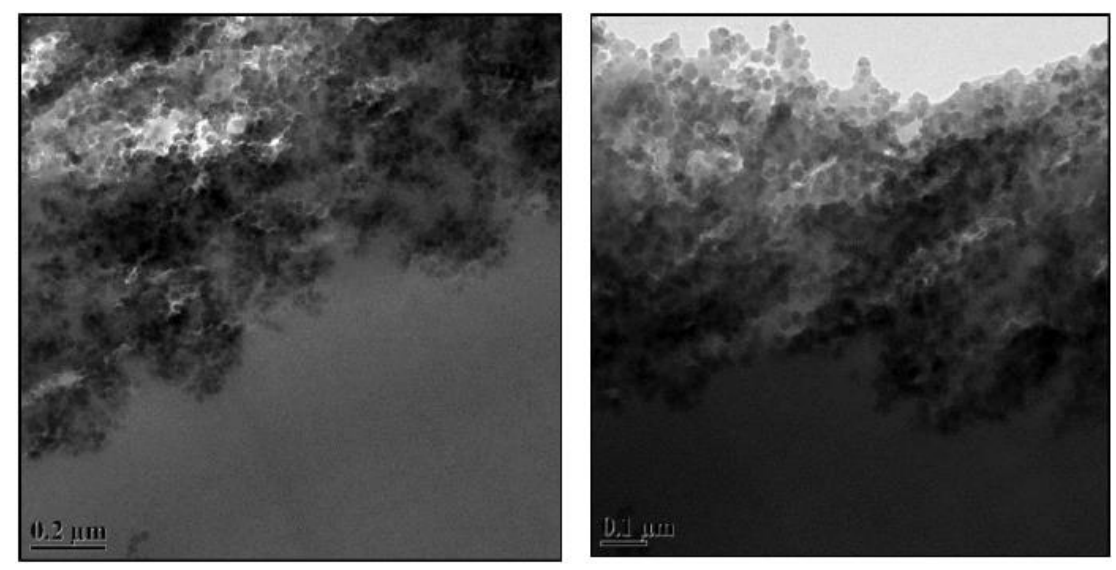

Figure 6. Cross-sectional view of microtomed sample of PU-5 wt \% silicone polyacrylate and 5 wt \% nano-silica particle dispersion.
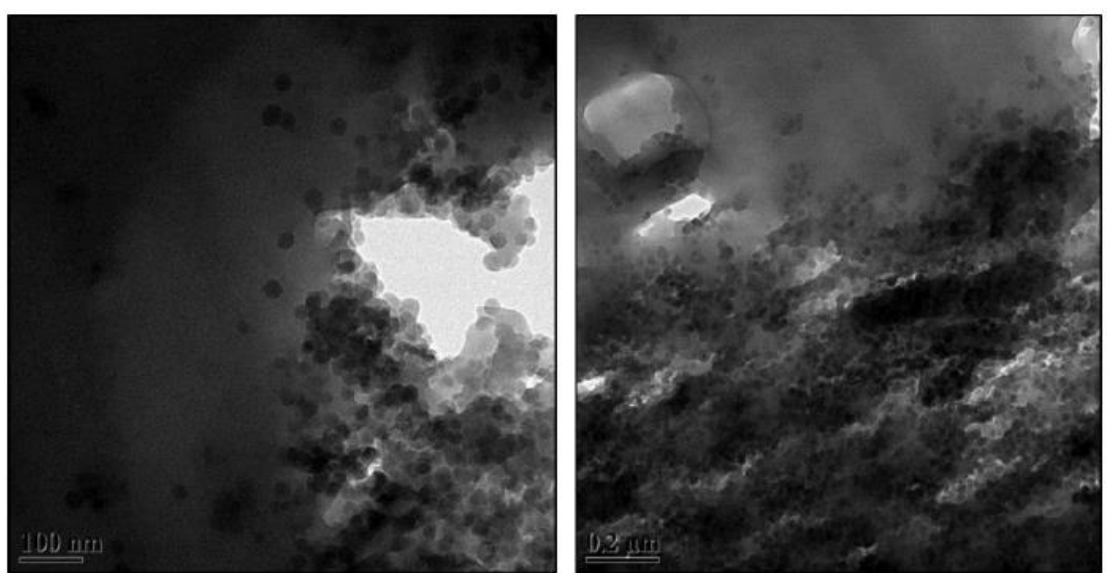

Figure 7. Cross-sectional view of microtomed sample of PU-5 wt \% silicone polyacrylate and 5 wt \% nano-silica particle dispersion. 
The trend of Surface hardness, elastic modulus and the coefficient of friction till $5 \mathrm{wt} \%$ nano-silica particles can be understood by considering the following phenomenon. Polymer structures are soft and their mechanical properties depend on their cross-linking density. Hence the addition of components which enhance their crosslinking density will help in enhancing their mechanical properties. Nanoparticle addition enhanced the cohesive forces within the polymer matrix to prevent sharp objects from indentation or polymer chain tearing. They increase the elastic modulus of the material. Elastic modulus affects the scratch process as penetration depth decreases with increase in the elastic modulus. Nanoparticles are used for this purpose because they as particles themselves have high hardness and elastic modulus. Their incorporation in the coating formulation was reported to be most effective [15]. The mechanism is shown in Figure 9. The coefficient of friction was observed to decrease with increase in the nano-silica particle content; this can directly be related to the scratch resistance. Lower the coefficient of friction, higher would be its scratch resistance.

The addition of nano-silica particles beyond $5 \mathrm{wt} \%$ deteriorated the mechanical properties because the particles started agglomerating and forming clusters which thereby led to the improper distribution of particles on the surface. These results can also be supported by the images seen in FEG-TEM analysis. Hence, 5 wt \% nanosilica particle dispersion was considered to be the optimum concentration in PU-5 wt \% silicone polyacrylate.

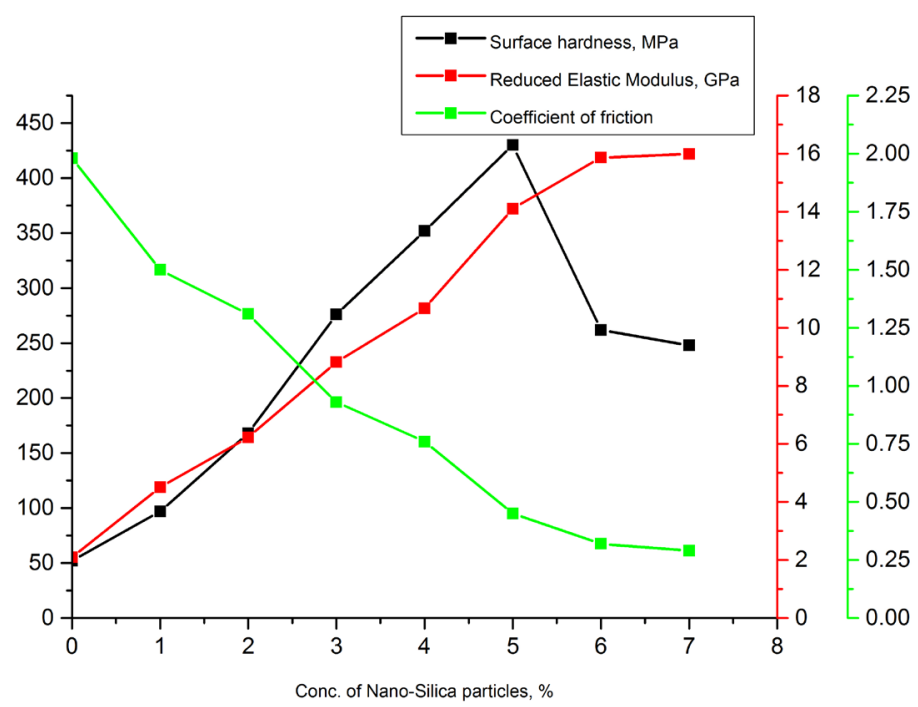

Figure 8. Plot showing a variation of Surface hardness, Elastic modulus and Coefficient of friction with varying content of Nano-silica particles.

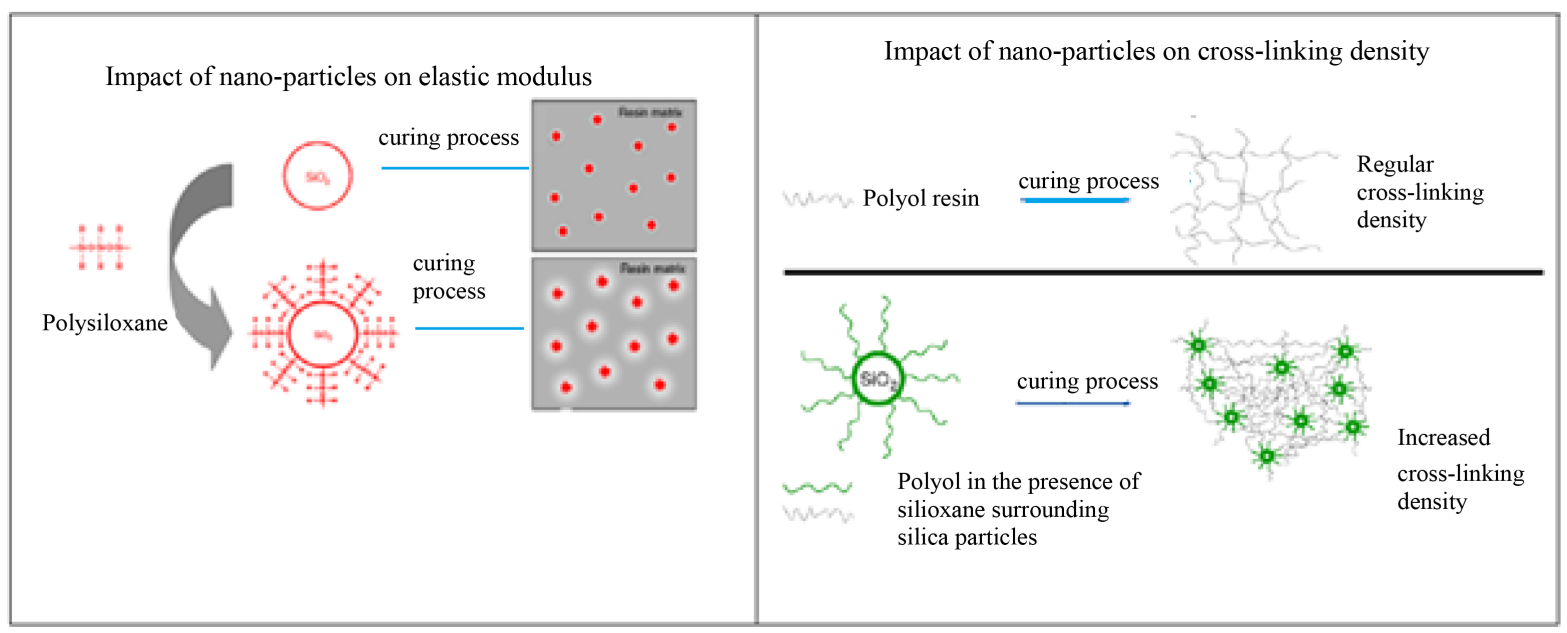

Figure 9. Effect of Nano-silica on elastic modulus and cross-linking density. 


\section{General Discussion}

Neat PU is hydrophilic in nature with water contact angle $72^{\circ}$ and contact angle of the spray paint being $71.3^{\circ}$. Incorporation of $\mathrm{OH}$-functional Silicone modified polyacrylate in neat PU has induced hydrophobicity. The migration of siliconated structure on to the surface lowered the surface energy of the coating. This did not allow water and the paint to penetrate through the coating. It also acted as a barrier by the preventing the pigments present in the paint to impregnate in the coating. As they were superficially adhered to the surface, they got easily erased during stain removal. The coating showed poor mechanical properties. From this we can infer that the addition $\mathrm{OH}$-functional Silicone modified polyacrylate in neat PU had showed no improvement mechanical properties.

Incorporation of nano-silica particles in the modified PU was done basically to improve the mechanical properties. These particles enhanced the cohesive forces within the polymer matrix, thereby making the polymer chain tearing difficult. These particles are very hard, their inclusion in the matrix made the overall matrix harder. Stress fields were developed around the particles in the matrix, this increased force required to cause indentation.

\section{Conclusion}

The PU based coating modified with polyacrylate was successfully formulated as anti-graffiti coating. It was observed that $5 \mathrm{wt} \%$ silicone polyacrylate showed maximum graffiti resistance. Contact angle of water and spray paint in neat PU increased from $72^{\circ}$ and $71.3^{\circ}$ to $103^{\circ}$ and $102.8^{\circ}$ respectively in PU-5 wt \% silicone polyacrylate. Stain removability of the coating at this concentration was almost 95\%. However anti-graffiti property decreased beyond $5 \mathrm{wt} \%$ polyacrylate addition due to accumulation of siliconated component on the surface which resulted in saturation. This was further modified by addition of nano-silica particles to increase the overall mechanical properties of the system. The effect of nano-silica particles on surface mechanical properties was observed to be maximum at $5 \mathrm{wt} \%$ concentration, beyond which properties deteriorated due to agglomeration. Hence 5 wt \% nano-silica particles in PU-5 wt \% silicone polyacrylate was considered to be the optimum formulation. Surface hardness improved from $52 \mathrm{MPa}$ to $430 \mathrm{MPa}$, Elastic Modulus increased from $0.7 \mathrm{GPa}$ to 14 GPa and Coefficient of friction decreased from 3.32 to 0.32 in case of neat PU to PU-5 wt \% silicone polyacryalate, 5 wt \% nano-silica particles formulation. This decrease in the coefficient of friction can be directly attributed to improvement in scratch resistance. It was also observed that nano-silica incorporation had no significant effect on graffiti resistance.

\section{References}

[1] Liu, H. (2013) Anti Graffiti Polyurethane Coating Containing Fluorocarbon Side Chains Grafted Polymethylsiloxane. Journal of Coatings Technology and Research, 10, 361-369. http://dx.doi.org/10.1007/s11998-012-9452-4

[2] Rabea, M. (2011) Investigating the Surface Properties of Polyurethane Based Anti-Graffiti Based Coatings against UV Exposure. Wiley Online Library.

[3] Gommans, L. (2000) Recent Advances in Polysiloxane Coatings. Corrosion Prevention and Control, 1, 72-82.

[4] Feng, L.L., Zhang, X.Y., Dai, J.B., Ge, Z., Chao, J. and Bai, C.Y. (2008) Synthesis and Surface Properties of Polyurethane Modified by Polysiloxane. Frontiers of Chemistry in China, 3, 1-5. http://dx.doi.org/10.1007/s11458-008-0001-8

[5] Rabea. M.. et al. (2012) Surface Analysis and Anti-Graffiti Behaviour of a Weathered Polyurethane-Based Coating Embedded with Hydrohphobi Nano Silica. Applied Surface Science, 258, 4391-4396. http://dx.doi.org/10.1016/j.apsusc.2011.12.123

[6] Dhoke, S.J. (2009) Effect of Nano-Alumina Particles on the Corrosion Behavior of Alkyd Based Waterborne Coatings. Coatings Technology, 6, 353-368.

[7] Swain, S., et al. (2013) Effects of Nano-Silica/Nano-Alumina on Mechanical and Physical Properties of Polyurethane Composites and Coatings. Transactions on Electrical and Electronic Materials, 14, 1-8.

[8] Rabea, A.M., Mohseni, M. and Mirabedini, S.M. (2011) Investigating the Antigraffiti Properties of a Polyurethane Clearcoat Containing a Silicone Polyacrlate Additive. Journal of Coatings Technology and Research, 8, 497-503.

[9] Wankhede, R.G. (2013) Development of Hydrophobic Inorganic-Organic hybrid Sol-Gel Coatings on Aluminium Using Nano Particles. IIT Bombay.

[10] Tarnowski, A., et al. (2007) Biodeterioration and Performance of Anti-Graffiti Coatings on Sandstone and Marble. Journal of ACCR, 32, 3-16. 
[11] Wypych, G. (2003) Handbook of Material Weathering. ChemTec Pub., Toronto.

[12] Ghermezcheshme, H., Mohseni, M. and Yahyaei, H. (2015) Use of Nanoindentation and Nanoscratch Experiments to Reveal the Mechanical Behavior of POSS Containing Polyurethane Nanocomposite Coatings: The Role of Functionality. Tribology International, 88, 66-75. http://dx.doi.org/10.1016/j.triboint.2015.02.023

[13] Lettieri, M. and Masieri, M. (2014) Surface Characterization and Effectives Evaluation of Anti-Graffiti Coatings on Highly Porous Stone Materials. Applied Surface Science, 288, 466-477. http://dx.doi.org/10.1016/j.apsusc.2013.10.056

[14] Barna, E. (2010) Synthesis and Characterization of Scratch Resistant Polyurethane Clear Coatings by Incorporation of Surface Modified Nanoparticles. University of Basel, Zurich.

[15] Chu, J., et al. (2000) Scratch Resistance of Mineral-Filled Polypropylene Materials. Polymer Engineering and Science, 40, 944-955. http://dx.doi.org/10.1002/pen.11222 